The Emotional Experience behind Sexually Offending in Context Affective States before, during, and after Crime Events

Leclerc, Benoit; Lindegaard, Marie Rosenkrantz

Published in:

Journal of Research in Crime and Delinquency

DOI:

$10.1177 / 0022427817743783$

Publication date:

2018

Document version

Peer reviewed version

Citation for published version (APA):

Leclerc, B., \& Lindegaard, M. R. (2018). The Emotional Experience behind Sexually Offending in Context:

Affective States before, during, and after Crime Events. Journal of Research in Crime and Delinquency, 55(2), 242-277. https://doi.org/10.1177/0022427817743783 
Leclerc, B. and Lindegaard, M.R. (2018) The emotional experience behind sexually offending in context: Affective states before, during, and after crime events. Journal of Research in Crime and Delinquency 55 (2): 242-277.

\section{The emotional experience behind sexually offending in context:}

\section{Affective states before, during, and after crime events}

Benoit Leclerc and Marie Rosenkrantz Lindegaard

\section{Introduction}

While rational choice has been the centre piece for situational prevention in the past thirty years (Clarke, 2014; Cornish \& Clarke, 2008; Leclerc \& Wortley, 2014), consideration of the role of affective states in offender decision-making models has been minimal in this area (van Gelder, Elffers, Nagin \& Reynald, 2014). As pointed out by van Gelder, Elffers et al. (2014), affective states consist of one critical dimension that can interfere with optimal offender decision-making. Affective states may cause someone to make the choice to commit a certain crime as well as influence the ways the crime is committed. In the field of sexual offending a substantive amount of research has given consideration to affective states for relapse prevention purposes and for developing typologies (e.g., Ward, Polaschek \& Beech, 2006), but affective states have not been examined in relation to offender decision-making of sexual offenders (Wortley \& Smallbone, 2014). Understanding the role of affective states for processes of decision-making is particularly important in relation to interpersonal crimes like sexual 
offending, because these crimes are known for being committed in a 'hot' rather than 'cold' state (van Gelder, 2013). While some scholars have argued that it does not even make sense to study decision-making processes in relation to interpersonal crimes because making any form of decisions is impossible when being wrapped up by emotions (de Haan \& Vos, 2003), we here propose turning this argument into an empirical question by investigating how affect may influence decision-making processes of sexual offenders. In addition, sexual offending provides a relevant case because previous studies emphasized that affective states, particularly anger and sexual excitement, play a role in crime commission, but these studies did not specify in what ways affective states play a role. In order to bring studies of affect and decision-making further we therefore study a crime for which it is recognized that affect plays a role. In order to investigate in what ways, we approach decision-making processes as related to different phases within the same criminal event, focusing on experiences of affective states immediately before, during, and after crime commission (see Lindegaard, Bernasco, Jacques \& Zevenbergen, 2014, on robbery) and examining whether situational factors may influence affective states throughout the crime event.

In order to develop effective intervention strategies to prevent sexual offending, both in terms of preventing the crime altogether and in terms of preventing the degree of harm while it takes place, it is essential to know how affective states may influence decision-making processes of offenders (see Bouffard, 2014; Topalli \& Wright, 2014). In terms of preventing the offense altogether, intervention programs for previous offenders would benefit from knowledge about the role and type of affective states not only during but also throughout the crime. In terms of preventing the degree of harm while it is taking place, research has shown that victims who clearly tell offenders to stop are likely to avoid further harm (e.g., Leclerc, Wortley \& 
Smallbone, 2011). This strategy for preventing harm may, however, be related to what type of affective state the offender experience and the context. For example, if the offender is angry addressing discomfort may lead to escalation whereas it may lead to prevention of the crime is the offender is ashamed. Therefore, knowledge on affective states of offenders in specific phases of the sexual offense, may be used to develop a "first aid kit" providing insights for victims about how to prevent harm in sexual offenses.

This study focuses on affective states experienced by adult male sexual offenders. We first identify both the type of affective state experienced by the offender as well as the specific moment in the decision-making process where the affect is described as influential immediately before, during or after the crime event. Specifically, we investigate whether a different affective state is experienced at particular time points during crime. Second, we analyze whether the affective states experienced by offenders vary throughout the event (i.e., immediately before, during and after). Third, we look at whether the emotional experience of offenders, immediately before, during or after the event, varies across different victims. Lastly, we investigate the possibility that a number of situational factors may influence affective states.

\section{Affective States and Offender Decision-Making}

Some may assume that rationality implies perfect reasoning and thus, leads to optimal decisions. There is no such thing as perfect human decision-making processes (Hastie \& Dawes, 2010). Even though offender decision-making is not the central focus of opportunity theories of crime, the idea of imperfect decision-making was made clear through the concept of bounded rationality since the birth of rational choice (e.g., Cornish \& Clarke, 1987; 2008). However, affective states experienced by offenders have not been incorporated successfully into this field. 
Clarke (2014) notes that knowledge on affective states and offender decision-making has increased substantially since rational choice was first formulated in criminology, which may explain in part why affective states have never been at the core of rational choice.

Affective states consist of one critical dimension that can impact how offenders reason during crime (van Gelder, Elffers et al., 2014) and therefore, shape crime commission substantially. Affective states are always present, which means that these will necessarily influence how the offender will behave during crime as well. As argued by Wortley (e.g., 1997; 2001), the immediate environment can precipitate (i.e., encourage or induce) individuals to commit a crime that they were not initially contemplating at that time, or even shape the severity of its outcome (Leclerc, Wortley \& Dowling, 2016). In other words, the environment provides opportunities to offend for already motivated offenders but also create or intensify the motivations to offend by generating a particular affective state(s), which then impacts on crime commission. Consistent with the principles of rational choice, Clarke (2014) adds that the role of affective states will be highly crime specific - for instance sexual arousal will be more critical in sexual offenses than any other offenses. Clarke further notes that that the transitory nature of certain affective states make them especially relevant to understand crime events and that affective states will vary across the different stages of the crime event (see Lindegaard et al., 2014, on armed robbery).

\section{The Cold and Hot Mode of Offender Decision-Making}

Carrying out crimes has been described as a highly emotional experience in a large variety of studies (de Haan \& Vos, 2003; Feeney 1986; Katz, 1988). However, emotions have rarely been the focus of any investigation on offender decision-making (van Gelder, 2013). In 
addition, current work on emotions has approached emotions as an outcome of offender decision-making rather than as a part of the process of making decisions (van Gelder, Elffers et al., 2014). Emotions were perceived as an actual or anticipated outcome of the decision to commit a crime rather than as an immediate effect on the moment of decision-making. In other words, if emotions were considered they were seen as something offenders wanted to achieve similar to money and status. However, emotions might also cause someone to make the choice to commit a certain crime as well as influence the way offenders behave during crime.

Emotions are one among other types of affective states that potentially influence offender decision-making. In addition to emotions, affective states also include moods and visceral factors. Moods are low in intensity and generally unrelated to a specific cause whereas emotions are intense, focused, and short-lived with a definite cause. Visceral factors can be characterized by certain moods and emotions; typical examples of visceral factors are sexual arousal, pain, hunger and drug craving (van Gelder, Elffers et al., 2014). For instance, Jacobs (1999) found that crack dealers commonly reported to not consume crack themselves as this habit would make them highly vulnerable to other offenders when selling drugs. Van Gelder (2013) argued that in order to understand the way mental processes guide offender decision-making, it is important to distinguish between hot and cold modes.

The cold, cognitive, mode is sensitive to considerations such as probabilities and extralegal costs such as anticipated guilt and social disapproval. Therefore, the cold mode is likely to respond to notions of sanction severity and certainty, as suggested by deterrence theorists. The cold mode is also responsible for weighing costs against benefits and making projections about the long-term consequences of decisions and, consequently, functions much in 
accordance with the logic assumed by rational choice models of offending. The hot mode, however, evaluates in a more intuitive way and responds to different situational characteristics, such as the temporal and spatial immediacy of decision outcomes, their controllability, and the vividness with which they can be imagined, but remains largely unresponsive to probabilities and outcomes themselves (van Gelder, 2013: 752)

A part of the process of offender decision-making might occur in a cold mode which allows for considerations of the outcomes of ones' actions including possible pain caused to victims and the risks of getting caught. However, as soon as the offender gets emotionally aroused as a consequence of the prospect of committing the crime or as a result of being in the stage of carrying it out, it is likely that the 'hotter' mode of mental processing would be activated. In this type of mode, weighting the costs against the benefits of ones' actions are difficult due to the tendency to focus on dealing with the actual situation. Whether the hot and cold processing of experiences work simultaneously or must be perceived as exclusive ways of processing is currently a topic for debate. In terms of offender decision-making, the crucial point is when offenders experience emotions characterized by intensity or are influenced by visceral factors like drug craving or sexual excitation. In this context, it is plausible to expect hot ways of processing decisions. If offenders report their affective state as a mood, one can expect cold information processing, which implies the ability to weigh up costs against the benefits. Offenders who, for instance, experience anger or sexual excitation before committing a crime will focus more on their immediate needs in the situation than on the long term implications of their choices. In order to determine how affective states influence offender decision-making in the first place it is important to identify both the type of affective state experienced by the 
offender as well as the specific moment in the decision-making process where the affect can shape behaviors - immediately before, during or after the crime event.

\section{Affective States in Sexual Offenses}

The theoretical and clinical importance of affective states in the field of sexual offending potentially emerged when Pithers first borrowed Marlatt's conceptualization of the relapse prevention process in individuals with an addiction and adapted it to the treatment of sexual offenders (Pithers, Marques, Gibat, \& Marlatt, 1983). Pithers, Kashima, Cumming, Beal and Buell (1988) noted that the transition from a high-risk situation to a lapse may be caused by personal deficits for coping with the situation that then leads to a negative emotion, such as loneliness and confusion. Other emotions such as anxiety were reported as a potential source of interference with the appropriate use of coping skills (McKibben, Proulx \& Lussier, 2001).

To further inform relapse prevention practices, Ward, Louden, Hudson and Marshall (1995) carried out a qualitative analysis of the pathways leading to child sexual offenses. They found a pathway characterized by a diversity of negative affective states (i.e., depression, anxiety and guilt), but also a pathway characterized by positive emotions and moods and sexual excitation. Building on Ward et al. (1995), a series of empirical studies have been completed over the years with both sexual offenders against women and children in which similar pathways have been observed (e.g., Hudson, Ward \& McCormack, 1999; Polaschek \& Hudson, 2004; Polaschek, Hudson, Ward \& Siegert, 2001; Ward et al., 2006). Furthermore, it has been suggested that certain emotions or moods could serve as a direct motivation for sexual offending (e.g., Serran \& Marshall, 2006). Indeed, many typologies also incorporated affective states as a key dimension in their development potentially acting as a motivator for sexually offending (e.g., 
Beauregard, Proulx, Brien \& St-Yves, 2005; Groth \& Birnbaum, 1979; Hall \& Hirschman, 1991;

1992; Knight \& Prentky, 1990). Affective states, such as sexual excitation and anger, are often at the core of these typologies.

\section{Sexual Offenders' Decision-Making during Crime Events}

Beauregard and Leclerc (2007) conducted a comprehensive study on sexual offenders' decision-making during crime events. Using a mixed-sample of serial sexual offenders against stranger women and/or children, they examined the rationales of offenders underlying their actions before, during and after the crime event. For instance, around 30\% of sexual offenders gave no thought to the risks of getting caught before or during crime potentially as a result of affective states. One offender explained: "You don't think about that, you don't have the time. It just happens and it's after when you cool down that this stuff comes up..." (p.121). For offenders who estimated their risk of getting caught (70\%), around half perceived this risk to be low. Offenders who perceived high risk of apprehension were concerned by factors, such as whether the victim had some information about them. Even if the victim knew their names, some offenders were simply not able to stop when the victim showed resistance again indicating the force of affective states. One offender mentioned: "I started to kiss her but she told me to stop. I was too wound up and there was no way I was going to stop there" (p.122). Following the event, most offenders did not move the victims (79\%) but some offenders released their victims in busy locations so that they could be helped (9\%). One offender explained: "I felt bad about it and I didn't want to leave her alone on the road..." (p.125). Even though this study focused on the rationales of offenders, the importance of affective states in sexual offenders' decision-making throughout the crime event still clearly emerged through the narratives of offenders. 


\section{The Unique Case of Sexual Excitation and Sexual Offenders' Decision-Making}

Sexual excitation, in particular, has been shown to have a substantial impact on decisionmaking. A number of studies have been conducted with male college students to understand the role of sexual excitation on the risk of sexually offending (e.g., Ariely \& Loewenstein, 2006; Bouffard, 2002; 2014; Exum \& Zachowicz, 2014; Loewenstein, Nagin \& Paternoster, 1997). Overall, the findings of these studies indicated that sexual excitation is likely to increase the use of force to obtain sexual contact - sexual excitation would alter the cognitive capacity to restraint from committing such an act. Recently, Exum and Zachowicz (2014) found evidence that sexual excitation may make the benefits-costs balance heavier on the benefits side by increasing the number of positive outcomes identified from memory, and by making them more accessible to the offender. In addition, sexual excitation may have the opposite effect when it comes to costs associated to the commission of a sexual offense. Consistent with this evidence, students who were sexually excited during the study also showed a higher likelihood of reporting the use of force to obtain sexual contact.

In the sexual offending literature specifically, Barbaree and Marshall (1991) conceptualized six models to explain the link between sexual excitation and sex offending against women. One of those models particularly focused on affective states in relationship to sexual excitation - the emotional state augmentation model. According to this model, nonsexual affective states modulate the strength of a sexual response. Strong positive feelings of love for a woman will increase the strength of the man's sexual arousal experienced in response to sexual interactions with her. However, feelings of hate and anger for a victim will also increase the strength of the offender's sexual excitation experienced during the aggression. In other words, 
the arousal to rape cues are boosted through the experience of negative affective states, which may characterize a number of sexual crime events.

In a recent empirical study on affective states of child sexual offenders, Wortley and Smallbone (2014) found that $37 \%$ of offenders were sexually excited before the offense. A positive association also suggested that sexual excitation would increase the risk of penetration. In addition, the findings indicated that physical attractiveness of the child may induce sexual excitation of the offender. With another sample of sexual offenders, Leclerc et al. (2016) discovered that sexual excitation was associated with increased use of force but only for stranger victims, which suggested that the role of sexual excitation should perhaps be understood within the broader context of the pre-existing offender-victim relationship.

\section{Current Study}

Firstly, we look at the recurrent presence of a wide range of affective states in sexual offending throughout the most recent crime event. Rather than examining which emotional experience may predominate for offenders during one sexual crime event, we break down the crime event into three stages (immediately before, during and after) under the assumption that offenders may experience a different affective state at each stage of the crime event. Secondly, we investigate the transition of affective states throughout the three stages for the most recent crime event. For instance, one offender may experience anger before the event, sexual excitation during the event, and anxiety after the event. Thirdly, we focus on each stage and examine transitions across different victims. Per example, we examine whether angry offenders before crime for victim 1 are also angry before crime for victim 2 and so on. Fourthly, we turn the spotlight on situational factors as potential predictors of affective states throughout the event. 
In this study, we are interested in examining the following questions:

Research question 1: What affective states, as experienced by adult sexual offenders, are most common immediately before, during and after the most recent crime event? We hypothesize that sexual offenders may more likely experience sexual excitation during the offense and shame/regret after the offense given what is currently known. However, it is rather difficult to pinpoint exactly which affective states will predominate others if any, and at which stage this may be the case;

Research question 2: Do affective states experienced by adult sexual offenders vary throughout the commission of an offense, that is, immediately before, during and after? We hypothesize that affective states experienced by sexual offenders should vary throughout crime (Clarke, 2014; Lindegaard et al., 2014). For instance, child sexual offenders may likely experience different affective states throughout the commission of a sexual offense (Ward et al., 2006) simply because the commission of the act itself is likely to have an impact on their affective states as well - for instance the experience of regret and shame after the offense;

Research question 3: Do affective states experienced by adult sexual offenders vary across victims? We may hypothesize that offenders will be likely to experience similar affective states at the same stage across victims - again this is largely based on relapse prevention models assuming that offenders may be likely to follow a specific pathway (or relapse process) across their victims. However, a situational perspective could also indicate that the situation would likely shape how the offender would behave - hence feel during the offense. In this context, the above hypothesis is tentative at best; 
Research question 4: What situational factors may influence affective states of sexual offenders in crime events? For instance, Wortley and Smallbone (2014) found some evidence that physical attractiveness and personality may actually be related to sexual excitation. A priori it makes sense to believe that physical attraction is related to sexual excitation, but in the context of offending, which includes time pressure, risk of being seen and apprehended and personal standards of morality to name a few, how sexual excitation may emerge is arguably more complex to uncover. Alcohol usage, risk of apprehension and offender-victim relationship are also situational factors that may influence the emergence of affective states at particular points during the event. We examine this question without formulating any clear hypothesis.

\section{METHOD}

\section{Sample}

The sample consisted of a total of 553 adult males who had been convicted of a sexual offense. These participants were assessed at the Regional Reception Centre of Ste-Anne-des-Plaines, Québec, a maximum-security institution of the Correctional Service of Canada where they underwent a six-week assessment of risk level and treatment needs prior to transfer to another institution. During this assessment, a semi-structured interview was completed with each participant for research purposes. The research protocols were conducted according to the ethical guidelines stipulated by the Research Ethics Board of the Université de Montréal during the time period in which the participants were interviewed. The majority of participants were Caucasian (87.8\%) and most had not completed high school education (78\%). A total of $42.5 \%$ of participants were single at the time of the offense and only $39.9 \%$ were employed. The average age of participants at the time of assessment was 40 years old ( $\mathrm{SD}=12.11)$. Their criminal history 
revealed that, on average, they were first convicted at 35.2 years old $(\mathrm{SD}=15.2$; range $=18.1$ 73.9). One-third of the sample had a prior conviction for a sexual offense. The number of victims refers to the total number of victims for the index offenses. On average, the participants included in this sample have been charged for 3.4 victims $(\mathrm{SD}=4.5$; range=2-65).

Offenders were interviewed for up to five victims and only the most recent victims were considered. If a victim had been abused multiple times only details of the most recent event was recorded. Most victims, from the first to the fifth victim, were Caucasian $(91 \%, 90.6 \%, 92.1 \%$, $92.2 \%, 88.9 \%$, respectively). In relation to the gender of victims, most were females $(81.7 \%$, $68.7 \%, 59.4 \%, 56.3 \%$, and $61.1 \%$, respectively) and known to the offender $(85.3 \%, 86.7 \%, 86 \%$, $82.8 \%$, and $86.1 \%$, respectively). Again from the first to the fifth victim, victims were also relatively young $($ Mean=16.58; $\mathrm{SD}=12.59 ;$ median $=13$, Mean=12.74, $\mathrm{SD}=9.44$ median $=11$, Mean=13.62; $\mathrm{SD}=12.41 ;$ median $=12$, Mean=14.59, $\mathrm{SD}=14.31$, median $=10.5$, Mean=13.11, $\mathrm{SD}=10.01$, median $=11$, respectively). In other words, sexual offenders against known young female best characterize this sample.

\section{Procedure}

All data used in this study were gathered through a semi-structured interview conducted with each participant using the QIDS (St-Yves, Proulx \& McKibben, 1994), which is a computerized questionnaire for sexual offenders. All interviewers were licensed forensic psychologists or criminologists. Participants granted access to their correctional files; official sources of information (e.g., police reports, victim statements, etc.) were also used to validate information, when possible, obtained in the interview. In case of disagreement between both sources, official data were prioritized. The quality of data collected from the QIDS was 
controlled by completing interrater agreement. Interrater agreement was measured on the basis of 16 interviews conducted jointly by two raters (the principal research assistant and the first author). Ratings were performed independently after these interviews, which were conducted by one interviewer in the presence of the other. The mean kappa was .87, which represents strong agreement. Finally, it should be noted that the average time that had passed between the moment when the interview took place and the most recent offense committed by offenders was 5.5 years $(\mathrm{SD}=8.0)$. The median was 2 indicating that half the sample had committed their most recent offense less than 2 years before the interview. The mode was 1 suggesting that most offenders had committed their offense only 1 year before the interview.

Participation in this study was strictly voluntary. Each participant was given an information sheet explaining the research project, its purpose and benefits for research, its potential consequences such as emotional stress on participants, and the contact details of the chief investigators. Each participant signed a consent form, which stated that the information would be used for research purposes only. No incentive was used.

\section{Affective State Variable and Analytical Strategy}

Affective states is the variable of interest in this study. Originally, a total of eleven affective states were included in the questionnaire. Specifically, offenders were asked to report how they were feeling for each stage of the crime event (i.e., immediately before, during, and after the offense) for their most recent victim(s) during an interview. They were provided with options consistent with the literature: anger, shame, regret, loneliness, sadness, anxiety, emptiness, confusion, calmness, well-being, and sexually excited. Note that offenders had also the opportunity to report affective states not included in the eleven options initially provided during the interview, but as eleven states were covered, no other state was reported. These 
affective states could be classified into three different categories: emotions (anger, shame, regret), moods (loneliness, sadness, anxiety, emptiness, confusion, calmness, well-being) and visceral state (sexual excitation) (see van Gelder, Elffers et al., 2014). As a result of the low sample size, and to perform the analysis, we regrouped the affective states that are similar in nature. The affective states used in the analysis were as follows: 1) anger, 2) shame/regret, 3) loneliness/sadness, 4) anxiety, 5) emptiness/confusion, 6) calmness/well-being, and 7) sexual excitation.

The first research question was examined through descriptive analysis. With respect to research questions 2 and 3, that is, the analysis of transitions of affective states throughout the crime event specifically - transition matrices were used. For question 2, 'affective state-switching patterns' were investigated in order to examine the tendency for sex offenders to experience a different affective state across the entire crime event for the same (and most recent) victim that is, immediately before, during and after the offense. Thus, we investigated transitions across the event: 1) from before to during the event, and 2) from during to after the event). With respect to question 3, the same analyses were performed but this time across victims for each stage of the event. Here, we focused on the first three victims only because the sample size was too small to consider the last two victims. In this sample, a total of 141 offenders were arrested for sexually abusing one victim, 211 offenders were arrested for sexually abusing two victims, 101 offenders for three victims, 64 offenders for four victims and 36 offenders for five victims. Because a number of cases were characterized by missing data on affective states, the sample size also varied across transitions. 
The last question involved the performance of regression analyses to investigate potential predictors of affective states for the most recent victim. Three dependent variables were created based on the prevalence of each affective state - one variable for each stage of the crime event. Firstly, a variable with three categories was created for the first stage of the crime, that is, before the event $(0=$ calm/well-being, $1=$ sexual excitation, $2=$ anger $)$. The other states were simply excluded from the analysis due to their low frequency. Secondly, a dichotomous dependent variable opposing sexual excitation and anger during the event was created $(0=$ sexual excitation, 1=anger). The other states were again excluded due to low frequency. Finally, a dichotomous variable opposing calm/well-being and shame/regret after the event was created $(0=$ calm/wellbeing, $1=$ shame/regret). The other states were again excluded based on the same rationale.

With regard to potential predictors, situational factors that may influence affective states were selected: Offender-victim relationship ( $0=$ family-related, $1=$ not family-related), alcohol intoxication $(0=$ no, $1=$ yes $)$, perceived risk of apprehension $(0=$ low, $1=$ high $)$, as well as victim personality attractiveness and victim physical attractiveness as continuous variables. In this sample, $47.6 \%$ of offenders were non-family related to their victim, $43.2 \%$ of offenders used alcohol and $38.9 \%$ reported high risk of apprehension when they committed their offense. For the last two variables, offenders were asked to rate from 1 to 10 the extent to which they were attracted to their victim - the higher the score the more attracted to the victim. The mean score obtained on physical attraction was $6.44(\mathrm{SD}=2.24, \mathrm{Med}=7)$. Similarly, the mean score obtained for personality attraction was $6.35(\mathrm{SD}=2.6, \mathrm{Med}=7)$.

\section{RESULTS}




\section{What affective states, as experienced by sexual offenders, are most common immediately before, during and after the offense?}

As can be seen in Figure 1, and as hypothesized, a number of affective states are experienced at different stages of the crime event. The moment during which certain affective states are experienced is easy to pinpoint - shame/regret is experienced only after the event (47.9\%). Sexual excitation is also experienced before (15\%), but mostly during the event (57.8\%). However, the exact moment(s) when other states may be experienced is not. For instance, loneliness/sadness is experienced only before the event (20.7\%). Similarly, emptiness/confusion is experienced only during (8.2\%) or after the event (5.8\%). Anger, anxiety and calmness/well-being are experienced throughout the event, that is, before, during and after the event. Anger seems to be more likely before $(22.3 \%)$ and during $(22.5 \%)$ rather than after the event (6.9\%). Anxiety is relatively uncommon, but experienced across the event (i.e., 13.6\%, $7.7 \%$ and $10.1 \%$, respectively). Calmness is more likely before (28.3\%) and after (29.4\%) rather than during the event (3.8\%). Overall, sexual offenders are more likely to experience loneliness, anger or calmness before the event. Sexual excitation dominates the other states during the event while shame/regret is the most likely affective state experienced after the event.

\section{INSERT FIGURE 1}

\section{Do affective states experienced by sexual offenders vary throughout the commission of an offense, that is, immediately before, during and after?}

Table 1 shows proportions of offenders who experienced specific affective states across the crime event for their most recent victim. Findings are overall consistent with our second hypothesis. As shown, affective states experienced by offenders fluctuate substantially across the 
event. For instance, $61 \%$ of offenders who were angry before the offense were still angry during the offense. For those who experienced a different affective state during the first transition, from before to during the event, $23 \%$ reported sexual excitation, $8 \%$ reported emptiness/confusion, $4 \%$ loneliness/sadness, 3\% shame/regret and $1 \%$ anxiety. In relation to the second transition, from during to after the event, $29 \%$ felt shame/regret, $12 \%$ experienced emptiness/confusion, $12 \%$ felt anxious and 5\% felt lonely/sad. However, 18\% experienced calmness/well-being after the event.

\section{INSERT TABLE 1}

Another good illustration of the fluctuation of affective states is emptiness/confusion. About $48 \%$ of offenders experienced this state both before and during the event. Of those who experienced a different affective state during the event, $24 \%$ reported anxiety, $12 \%$ anger, $8 \%$ sexual excitation, $4 \%$ calmness/well-being and $4 \%$ loneliness/sadness. However, most offenders who experienced either shame/regret or loneliness/confusion during the event experienced the same state after the event (78\% and $75 \%$, respectively). It should be noted here that the total sample size in this case was very small ( 9 and 4 , respectively).

Interestingly, sexual excitation was the most stable affective state throughout the entire crime event. Of offenders who were sexually excited before the event, $94 \%$ were also sexually aroused during the event. Not surprisingly none who experienced sexual excitation during the event were sexually excited after the event. The most common affective states after the event reported by offenders who were sexually excited during the event were: 1) shame/regret (47\%), 2) calmness/well-being (36\%), 3) anxiety (10\%), 4) anger (2\%), 5) loneliness/sadness (2\%), and 6) emptiness/confusion (1\%). Note that no offender experienced shame/regret or loneliness/sadness before the event. 


\section{Do affective states experienced by sexual offenders vary across victims?}

Contrary to what was found when looking at the fluctuations of affective states throughout the crime event for the most recent victim, Table 2 indicates very little variation across victims for the same offender before the event. Offenders who experienced anger, emptiness/confusion or anxiety tended to experience the same affective state across victims for that particular stage. Similarly, very little variation of other affective states was observed. Table 3 depicts a similar pattern for affective states across victims experienced during the event. Very little variation occurred. Offenders who experienced sadness/loneliness or anxiety in this stage tended to feel the same way across victims as well. In addition, most offenders felt sexually excited during this stage, which was still the case across victims. Table 4 also exhibits this pattern for affective states across victims experienced after the event. Very little variation was observed. Most offenders experienced either shame/regret or calmness/well-being, which did not fluctuate considerably across victims.

INSERT TABLES 2, 3 and 4

As we used seven affective states in the analysis, we also expected a high number of combinations between affective states across the crime event (before, during and after) in the sample. We focused only on the most recent victim and found as many as 93 combinations (or pathways) with a sample of 342 cases, suggesting the high variability of affective states across sexual offenders. For reasons of space, these configurations of affective states throughout the event are not presented here but available upon request.

What situational factors may influence affective states of sexual offenders in crime events? 
In this section, the spotlight is turned on the potential influence of a number of situational factors on affective states. We looked at the impact of these factors on affective states using the most prevalent affective states at each stage of the crime event as dependent variables. Due to the low sample size for certain affective states across the sample, this analysis was performed for the most recent victim only. Table 5 indicates that offenders who used alcohol before crime were more likely to be angry than either calm $(\mathrm{OR}=.285)$ or sexually excited $(\mathrm{OR}=.324)$ before crime. In addition, offenders who abused a non-family related victim were more likely to be calm than angry before crime $(\mathrm{OR}=2.27)$. Table 6 reports that as the degree of personality attractiveness of the victim increased offenders were more likely to be sexually excited than angry during crime $(\mathrm{OR}=.858)$. In addition, offenders who used alcohol were more likely to be angry than sexually excited during crime $(\mathrm{OR}=4.55)$. Table 7 shows that offenders who were not family-related to their victim were more likely to be calm than experience shame and regret after the event $(\mathrm{OR}=.534)$.

INSERT TABLES 5, $6 \& 7$

\section{DISCUSSION}

The current study focused on the role of affective states in adult sexual offending. We first looked at the prevalence of a range of affective states throughout the event. We then broke down the crime event into three stages, that is, immediately before, during and after the offense. We examined transitions of affective states throughout the crime event - stage by stage - for the most recent victim only but also across victims. Finally, we turned our attention to predictors of affective states throughout the crime event. 
The first research question looked at the most common affective states at each stage of the crime event. As expected, we found that sexual excitation was common during the offense and shame/regret was often experienced after the offense. Anger and calmness (and consider loneliness and sexual excitation) were most common immediately before the event. The dimension of sexual excitation is always of importance for sexual offenders, but difficult to fully understand 'in action'. Only $12.4 \%$ of offenders indicated experiencing sexual excitation immediately before the offense, which appears puzzling at first sight. Wortley and Smallbone (2014) reported a larger proportion of sexually excited offenders before the offense even though this proportion was still relatively low at $37 \%$. However, the proportion of sexually excited offenders during the offense increased to nearly $60 \%$ in this study, which seems to make more sense even though a much larger proportion could still be expected. As reported by Wortley and Smallbone (see also Leclerc et al., 2016), offenders may deny or minimize the presence of sexual excitation to project a positive image of themselves or may have had difficulties of identifying how they felt when they committed their offense. In addition, offenders may have experienced sexual excitation only during sexual activities. However, in the case of non-sexually excited offenders during the offense, it is possible that some offenders did not experience sexual excitation because they were under a more powerful state, such as anger. Anger may overpower sexual excitation in some cases. For instance, van Gelder, Reynald and Elffers (2014) found that other affective states such as anticipated shame lose their effect under anger conditions.

The second question looked at the transitions of affective states from one stage to another throughout the event for the most recent victim. Even though some patterns of affective states could be identified, variability best characterized the emotional experience of offenders throughout sexual crime events. In addition, if sexual excitation is taken as a visceral factor 
rather than classified as a 'positive' affective state, more variability is highlighted - mixed pathways seem more likely in this context (Ward et al., 2006). In light of this result, it further appears that only a minority of offenders would actually experience the same affective state throughout the entire event, which immediately raises questions on the accuracy and validity of sex offenders' typologies based on a single affective state and highlight the relevance of breaking down the event to study affective states. The fluctuation of affective states throughout the crime event also points to the relevance of looking at the interactive interplay between affective states, situational cues, criminal opportunities and how offenders may behave during crime (see Topalli \& Wright, 2014).

If how one sex offender feels is likely to vary throughout a single crime event (e.g., see van Gelder, 2013; van Gelder, Reynald \& Elffers, 2014), sexual offenders may be likely to weigh up the costs of committing crime at particular time points. 'Colder' ways of processing, which may involve being calm before the event, may represent potential intervention points for offenders to disrupt their offending before they get sexually excited and approach a potential victim. Indeed, under such affective states sex offenders may be more likely (and capable) to consider negative consequences related to offending. As indicated by van Gelder (2013), sexual excitation should lead to hot ways of processing, which implies that sexual offenders when aroused will be less likely to see the long-term consequences of offending being absorbed by the need of immediate sexual gratifications. Thus sexually excited offenders are less likely to refrain from committing the crime or stop during the actual offending, which leaves the stage before the event as a critical point for disruption from an intervention point of view. This also brings the question of whether the hot and cold modes of processing overlap during the event as well (e.g., see van Gelder, 2013; van Gelder, Reynald \& Elffers, 2014). Whether hot and cold modes of 
processing overlap, or an offender can experience both modes simultaneously, has to be clarified in future studies because the presence of cold mode may represent a way for the offender to neutralize the hot mode of processing.

The third research question examined whether sexual offenders would experience the same affective state across different victims. We found that offenders are likely to experience a similar affective state across victims, which is consistent with the relevance of identifying relapse prevention models on an individual basis. However, the data used in this study were collected through a cross-sectional design, thus providing only a limited timeframe during which offenders could have offended. Therefore, it is also possible that offenders may experience different affective states for different victims at quite distinct life periods. In addition, this finding is somewhat inconsistent with the assumption made by Wortley and Smallbone (2014) that the first ever offense committed by an offender involves different situational cues or motivations and affective states than subsequent offenses. However, the survey used to collect data in this study only gathered offense details for officially reported offenses, which means that a number of 'first ever offenses' may not have been captured if they were not recorded by authorities. Another possibility is that affective states are unlikely to vary across victims, but situational elements that may trigger sexual thoughts or desires to obtain sexual contact with children or nonconsensual women may vary for the first offense - which is consistent with the assumption of Wortley and Smallbone.

The last question investigated whether situational factors could act as potential predictors of affective states. Alcohol emerged as a critical predictor before and during the event. Alcohol usage was more likely in the case of angry offenders compared to calm or sexually excited 
offenders before the event. Alcohol consumption was also more likely in the case of anger compared to sexual excitation during the event. Ullman (2007) reported that alcohol's role in sexual offenses is still unclear but nevertheless associated with penetration and physical injuries (see also Balemba \& Beauregard, 2012; Martin \& Bachman, 1998). In fact, alcohol decreases men's social inhibitions against using violence, which in turn may increase the risk of physical injuries (Leclerc et al., 2016; Marshall \& Barbaree, 1990). As a partial explanation, it can be argued that alcohol usage may boost or even trigger anger conditions for offenders who are looking for retribution or punishment especially for those against women, which may explain why alcohol is commonly associated with the use of violence and physical injuries in sexual offenses in the first place.

Offender-victim relationship is another important factor for explaining affective states before and after the event. Offenders who were not family-related to their victim were most likely to be calm than angry before the event and more likely to be calm than experience shame after the event. Overall this indicates that extrafamilial offenders are more likely to display a positive rather than a negative affect overall when offending compared to intrafamilial offenders. As intrafamilial offenders are, by definition, family-related to their victim, many of them may be more likely to experience shame after the offense than extrafamilial offenders. Moreover, in many intrafamilial sexual offenses (e.g., between adult partners), negative affective conditions, such as anger, may temporarily neutralise the existing bond between the offender and the victim to make crime possible (van Gelder, Reynald \& Elffers, 2014). Anger could suppress positive feelings related to familial bonds for the time that crime is committed. Importantly, this study shows that the nature of the relationship between the offender and the victim not only help 
understand how the offender will behave but also feel throughout the offense, which shapes crime commission processes.

Apart from gaining a deeper understanding of the role and type of affective states in sexual offending, there are potential intervention/prevention implications related to investigating affective states even though the present study offers insights on a topic rarely examined from a crime event analysis point of view. For instance, a more comprehensive integration of the role and type of affective states with situational factors at different stages of the crime event for programs practicing relapse prevention with offenders could be emphasized - this is consistent with the work of Ward and his colleagues on offending pathways (Ward et al., 2006). The most common transitions of affective states identified in this study could be utilized as a baseline model against which to investigate the emotional experience of offenders during offending. Important influential situational factors, such as alcohol usage and offender-victim relationship, could also be mapped onto these transitions to develop more comprehensive models aimed at reducing risk of re-offending.

In terms of preventing crime or reducing its degree of harm when taking place, providing evidence-based advises to potential victims could be a priority. Although this clearly requires further empirical research, self-protection programs aimed at women particularly could incorporate knowledge on what type of affective state sexual offenders may experience at different stages of the crime event. In turn, this knowledge may be useful for potential victims to make better decisions on how to react if attacked by an offender (see Smith, 2009). Knowledge on affective states of offenders in specific stages of the sexual offense, may be used to develop a "first aid kit" providing insights for potential victims about how to avoid victimization or prevent 
harm in sexual offenses. This suggestion falls under a situational crime prevention framework most specifically target hardening. In addition, increasing the efforts and risks of offending may push back the precipitating effects that some affective states, such as anger and sexual excitation, may have on offending. Techniques such as removing excuses and reducing provocations to offend might also be used to offset the impact that these affective states may have on the likelihood that one offender offends to the extent of stopping crime before its initiation (Cornish \& Clarke, 2003; Wortley, 2001).

Educating potential victims can also be extended to potential guardians/bystanders who may intervene during sexual offenses - to the ordinary citizen. Per example, Reynald (2010) observed that the sense of responsibility that people feel for protecting others in their immediate surroundings plays a critical role both in their willingness to supervise and their willingness to intervene during crime. Therefore, informing ordinary citizens on how sex offenders feel and associated situational factors throughout the offense may boost their sense of responsibility and therefore their willingness to intervene if a sexual offense occurs in their presence (see also Leclerc \& Reynald, 2015). The above discussion is obviously preliminary at this stage given the current lack of empirical research on the role of affective states on offender decision-making but nonetheless sufficient to demonstrate the relevance of examining affective states of offenders for practical purposes (van Gelder, Elffers et al., 2014).

\section{Limitations}

Like any studies, this study contains limitations. First, a total of eleven affective states were identified in this study: anger, shame, regret, loneliness, sadness, anxiety, emptiness, confusion, calmness, well-being, and sexually excitation. As the sample size was low for certain 
affective states, we had to regroup those that were relatively similar in nature for conducting transition matrices and regression analyses. It is possible that this methodological operation influenced the findings. Second, this study is based on self-report data, which means that some findings may be biased by offenders' cognitive distortions. For instance, it is possible that some offenders, in order to present a positive image of themselves, reported that they were not sexually excited before the offense even if they were - a sensitive topic from the offender's point of view.

It is important to note that one of the reasons why the crime event was broken down into three separate stages in this study (before, during and after) was to collect reliable and precise information as much as possible from offenders. First, this method is not only consistent with a criminological analysis of crime events, but also neutralizes possible limitations that may arise if offenders were only asked to report one affective state for the crime event taken as a whole (in this context offenders would easily overlook to report different affective states experienced during crime). Second, this method also partially offsets the impact that memory recall may have on the findings. Many offenders may have experienced difficulties in recalling how they felt emotionally at the time of the offense, which may in turn affect the findings. However, memory recall should arguably have less impact in this study because the event was broken down into three separate stages offering a cognitive structure to offenders to facilitate recall on their emotional experience during offending. In addition, the mode for the time that had passed between the moment when the interview took place with offenders and their most recent crime was only 1 year, which suggests that most offenders had committed their offense only 1 year before the interview. Furthermore, only transition matrices conducted on affective states across 
victims (see Tables 2-4) involved data collected for different victims, which implies that memory recall is most likely to have an impact only on these later analyses if any.

Finally, it is not impossible that some offenders may have felt more than one affective state at one particular stage of the crime event but failed to report it, but this possibility is very difficult to measure. First, this possibility brings the question of whether different modes of processing overlap during the event as well or simply overcome each other so that only a single state drives the offender at one point in time. However, at the moment, as noted by researchers in this area (e.g., see van Gelder, 2013; van Gelder, Reynald \& Elffers, 2014), it is unclear how affective states interact with each other in time and space if they do so, which implies that the impact of this potential limit if any is hard to assess. In fact, the literature suggests that some affective states may simply suppress other states (rather than co-exist) under specific conditions (van Gelder, Reynald \& Elffers, 2014). Second, it can be argued that the only way to collect data on the offender's affective states is through his/her accounts. Simply put "criminals know things about crime that others do not see" (Jacques \& Wright, 2010: 23), which is the case here. Therefore, even though it is not impossible that some offenders may have felt more than one affective state at one stage of the crime event but did not disclose this information, self-reported data remains the only method to examine affective states of offenders despite the limitations inherent and commonly related to this data source.

\section{CONCLUSIONS}


Committing crimes is a highly emotional experience and sexual offenses are no exception. Affective states of sexual offenders vary within the crime event with anger, calmness, loneliness and sexual excitation were common before the offense, sexual excitation was common during the offense, and shame/regret was common after the offense. Across events offenders described little variation in their affective states. Situational factors, such as alcohol usage and offender-victim relationship were related to affective states at different points during crime.

Our findings highlight the importance of paying attention to the role of affective states for sexual offenders' decision-making. Offender descriptions of affective states provide insights into their perceptions of opportunities and constraints in the situation, and this in turn reveals why and how they make certain choices. However, clarifying the decision-making process of offenders is a very difficult task and there is little research on this topic in sexual offending. Therefore, a number of questions beg for future research. Questions that need to be addressed in future studies involve the causal mechanisms between affective states and the decisions made by offenders. Our success with gaining insights about specific phases (before, during, after) within crime events is promising for such detailed investigations of offender decision-making. This study calls for giving consideration to the role played by affective states in adult sexual offenders during crime events.

While our study clearly emphasizes the importance of paying attention to the unfolding of crime events, and the way affective states change within them, it is still based on retrospective studies known for being biased because of social desirability answers and memory failures. For instance, and as a complement, it may be suggested that future studies of the role of affective states in decision-making within crime events draw on CCTV crime footage. The advantage of 
such data is perhaps a more reliable measurement of behavior within crime events, including the possibility of analysing non-verbal expression of emotions of offenders and other parties involved. Sexual offenses may not be likely to be caught on camera. Therefore, the study of affective states in other types of crimes like assaults and robbery may form the basis for hypothesis development that in turn may be tested in studies of sexual offenses. The most revealing point to remember from our analysis is the potential power that affective states may have on sexual offenders' decision-making and crime commission supporting the relevance and the need for future research on the role and type of affective states in crime events.

\section{REFERENCES}

Ariely, D., \& Lowenstein, G. (2006). The heat of the moment: The effect of sexual arousal on sexual decision making. Journal of Behavioral Decision Making, 19, 87-98.

Balemba, S., \& Beauregard, E. (2012). Reactions to resistance: The role of contextual factors in sex offending. Violence and Victims, 27, 148-165.

Beauregard, E., \& Leclerc, B. (2007). An application of the rational choice approach to the offending process of sex offenders: A closer look at the decision-making. Sexual Abuse: A Journal of Research and Treatment, 19, 115-133.

Beauregard, E., Proulx, J., Brien, T., \& St-Yves, M. (2005). Deux types de meurtriers sexuels: Le colérique et le sadique. In J. Proulx, M. Cusson, E. Beauregard \& A. Nicole (Eds.), Les meutriers sexuels: Analyse comparative et nouvelles perspectives (pp. 203-232). Montréal, Canada: Les Presses de l'Université de Montréal. 
Bouffard, J. (2002). The influence of emotion on rational decision making in sexual aggression. Journal of Criminal Justice, 30, 121-134.

Bouffard, J. (2014). The role of sexual arousal and perceived consequences in men's and women's decisions to engage in sexually coercive behaviors. In J-L. Van Gelder, H. Elffers, D. Nagin \& D. Reynald (Eds.), Affect and Cognition Affect and Cognition in Criminal Decision Making: Between Rational Choices and Lapses of Self-Control (pp. 77-96). London: Routledge.

Clarke, R.V. (2014). Affect and the reasoning criminal: Past and future. In J-L. Van Gelder, H. Elffers, D. Nagin \& D. Reynald (Eds.), Affect and Cognition Affect and Cognition in Criminal Decision Making: Between Rational Choices and Lapses of Self-Control (pp. 20-41). London: Routledge.

Cornish, D. B. \& Clarke, R.V. (1987). Understanding crime displacement: An application of rational choice theory. Criminology, 25, 933-947.

Cornish, D.B. \& Clarke, R.V. (2003). Opportunities, Precipitators and Criminal Decisions: A Reply to Wortley's Critique of Situational Crime Prevention. In M. Smith and D. B. Cornish (Eds.) Crime Prevention Studies, Theory for Practice in Situational Crime Prevention. Vol. 16. Monsey, NY: Criminal Justice Press.

Cornish, D. B., \& Clarke, R. V. (2008). The rational choice perspective. In R. Wortley \& L. Mazerolle (Eds.), Environmental criminology and crime analysis (pp. 21-47). Cullompton, UK: Willan.

De Haan, W. \& Vos, J. (2003). A crying shame: The over-rationalized conception of man in the rational choice perspective. Theoretical Criminology, 7, 29-54. 
Exum, M. L., \& Zachowicz, A. (2014). Sexual arousal and the ability to access sexually aggressive consequences from memory. In J-L. Van Gelder, H. Elffers, D. Nagin \& D. Reynald (Eds.), Affect and Cognition Affect and Cognition in Criminal Decision Making: Between Rational Choices and Lapses of Self-Control (pp. 97-118). London: Routledge.

Feeney, F. (1986). Robbers as decision-makers. In D. Cornish and R.V.G. Clarke (Eds.) The reasoning criminal: Rational choice perspectives on offending (pp.53-71). New York: Springer-Verlag.

Groth, A. N., \& Birnbaum, H. J. (1979). Men who rape: The psychology of the offender. New York, NY: Plenum.

Hall, G. C. N., \& Hirschman, R. (1991). Toward a theory of sexual aggression: A quadripartite model. Journal of Consulting and Clinical Psychology, 59, 662-669.

Hall, G. C. N., \& Hirschman, R. (1992). Sexual aggression against children: A conceptual perspective of etiology. Criminal Justice and Behavior, 19, 8-23.

Hastie, R., \& Dawes, R. M. (2010). Rational choice in an uncertain world: The psychology of judgement and decision making ( $2^{\text {nd }}$ edition). Los Angeles, California: Sage Publications.

Hudson, S. M., Ward, T., \& McCormack, J. C. (1999). Offense pathways in sexual offenders. Journal of Interpersonal Violence, 14, 779-798.

Jacobs, B. (1999). Dealing crack: The social world of streetcorner selling. Boston: Northeastern University Press. 
Jacques, S., \& Bonomo, E. (2016). Learning from the Offenders' Perspective on Crime

Prevention. In B. Leclerc and E. Savona (Eds.), Crime Prevention in the $21^{\text {st }}$ Century, pp. 9-

17. New York: Springer.

Katz, J. (1988) Seduction of crime: Moral and sensual attraction in doing evil. New York:

Basic Books.

Knight, R., \& Prentky, R. (1990). Classifying sexual offenders: The development and corroboration of taxonomic models. In W. L. Marshall, D. R. Laws \& H. E. Barbaree (Eds.), The handbook of sexual assault: Issues, theories, and treatment of the offender (pp. 23-52). New York:

Plenum.

Leclerc, B. \& Reynald, D. (2015). When scripts and guardianship unite: A script model to facilitate intervention of capable guardians. Security Journal (DOI:10.1057/sj.2015.8).

Leclerc, B. Smallbone, S., \& Wortley, R. (2014). Interpersonal scripts and victim reaction in child sexual abuse: A quantitative analysis of the offender-victim interchange. In B. Leclerc \& R. Wortley (Eds.), Cognition and crime: Offender decision-making and script analyses (pp.102119). Crime Science Series, London, UK: Routledge.

Leclerc, B., \& Wortley, R. (2014). The reasoning criminal: Twenty-five years on. In B. Leclerc \& R. Wortley (Eds.), Cognition and crime: Offender decision-making and script analyses (pp. 1- 11). New York: Routledge.

Leclerc, B., Wortley, R. \& Smallbone, S. (2011). Victim resistance in child sexual abuse: A look into the efficacy of self-protection strategies based on the offender's experience. Journal of Interpersonal Violence, 26, 1868-1883. 
Leclerc, B, Wortley, R., \& Dowling, C. (2016). Situational precipitators and interactive forces in sexual crime events involving adult offenders. Criminal Justice \& Behavior. (doi:10.1177/0093854816660144).

Lindegaard, M. R., Bernasco, W., Jacques, S., \& Zevenbergen, B. (2014). Posterior gains and immediate pains: Offender emotions before, during and after robberies. In J-L. Van Gelder, H. Elffers, D. Nagin \& D. Reynald (Eds.), Affect and Cognition Affect and Cognition in Criminal Decision Making: Between Rational Choices and Lapses of Self-Control (pp. 5876). London: Routledge.

Loewenstein, G., Nagin, D., \& Paternoster, R. (1997). The effect of sexual arousal on expectations of sexual forcefulness. Journal of Research in Crime and Delinquency, 34, 443-473.

Marshall, W. L., \& Barbaree, H. E. (1990). An integrated theory of sexual offending. In W. L. Marshall, D. R. Laws \& H. E. Barbaree (Eds.), Handbook of sexual assault: Issues, theories, and treatment of the offender (pp. 257-275). New York: Plenum Press.

Martin, S., \& Bachman, R. (1998). The contribution of alcohol to the likelihood of completion and severity of injury in rape incidents. Violence Against Women, 4, 694-712.

McKibben, A., Proulx, J., \& Lusignan, R. (2001). Relationship between conflict, affect and deviant sexual behaviors in rapists and pedophiles. Behavior Research and Therapy, 32, $571-575$.

Pithers, W. D., Kashima, K. M., Cumming, G. F., Beal, L. S., \& Buell, M. M. (1988). Relapse prevention of sexual aggression. Annals in New York Academy of Sciences, 528, 244-260. 
Pithers, W. D., Marques, J. K., Gibat, C. C., \& Marlatt, G. A. (1983). Relapse prevention with sexually aggressive: A self-control model of treatment and the maintenance of change. In J. G. Greer \& I. R. Stuart (Eds.), The sexual aggressor: Current perspectives on treatment (pp. 214-234). New York: Van Nostrand Reinhold.

Polaschek, D. L. L., \& Hudson, S. M. (2004). Pathways to rape: Preliminary examination of patterns in the offense processes of rapists and their rehabilitation implications. Journal of Sexual Aggression, 10, 7-20.

Polaschek, D. L. L., Hudson, S. M., Ward, T., \& Siegert, R. J. (2001). Rapists' offense processes: A preliminary descriptive model. Journal of Interpersonal Violence, 16, 524544.

Reynald, D. M. (2010). Guardians on guardianship: Factors affecting the willingness to supervise, the ability to detect potential offenders, and the willingness to intervene. Journal of Research in Crime and Delinquency, 47, 358-390.

Serran, G. A., \& Marshall, W. L. (2006). Coping and mood in sexual offending. In W. L. Marshall, Y. M. Fernandez, L. E. Marshall \& G. A. Serran (Eds.), Sexual offender treatment: Controversial issues (pp. 109-124). Chichester, England: John Wiley \& Sons.

Smith, M. (2009). A six-step model of potential victims' decisions to change location. Security Journal, 22, 230-249.

St-Yves, M., Proulx, J., \& McKibben, A. (1994). Questionnaire informatisé sur les délinquants sexuels (Computerized Questionnaire for Sexual Offenders). Unpublished document. Correctional Service of Canada. 
Topalli, V., \& Wright, R. (2014). Affect and the Dynamic Foreground of Predatory Street Crime: Desperation, Anger, and Fear. In J-L. Van Gelder, H. Elffers, D. Nagin \& D. Reynald (Eds.), Affect and Cognition Affect and Cognition in Criminal Decision Making: Between Rational Choices and Lapses of Self-Control (pp. 42-57). London: Routledge.

Ullman, S. E. (2007). A 10 -year update of "Review and critique of empirical studies of rape avoidance". Criminal Justice and Behavior, 34, 411-429.

Van Gelder, J.-L. (2013). Beyond rational choice: The hot/cool perspective of criminal decision making. Psychology, Crime \& Law, 19, 745-763.

Van Gelder, J.-L., Elffers, H., Nagin, D., \& Reynald, D. (2014) (Eds.). Affect and Cognition in Criminal Decision Making: Between Rational Choices and Lapses of Self-Control. London: Routledge.

Van Gelder, J.-L., Reynald, D., \& Elffers, H. (2014). Anticipated emotions and immediate affect in criminal decision making: From shame to anger. In J-L. Van Gelder, H. Elffers, D. Nagin \& D. Reynald (Eds.), Affect and Cognition Affect and Cognition in Criminal Decision Making: Between Rational Choices and Lapses of Self-Control (pp. 161-178). London: Routledge.

Ward, T., Louden, K., Hudson, S., \& Marshall, W. L. (1995). A descriptive model of the offense chain for child molesters. Journal of Interpersonal Violence, 10, 452-472.

Ward, T., Polaschek, D. L. L., \& Beech, A. R., (2006). Theories of sexual offending. Chichester, England: John Wiley \& Sons. 
Wortley, R. (1997). Reconsidering the role of opportunity in situational crime prevention. In G. Newman, R. V. Clarke \& S. G. Shoham (Eds.), Rational choice and situational crime prevention (pp. 65-81). Aldershot: Ashgate.

Wortley, R. (2001). A classification of techniques for controlling situational precipitators of crime. Security Journal, 14, 63-82.

Wortley, R., \& Smallbone, S. (2014). Emotional arousal and child sex offending: A situational perspective. In J-L. Van Gelder, H. Elffers, D. Nagin \& D. Reynald (Eds.), Affect and Cognition Affect and Cognition in Criminal Decision Making: Between Rational Choices and Lapses of Self-Control (pp. 119-139). London: Routledge.

Figure 1. Percentage of sexual offenders who experienced affective states before, during and after sexual crime events 


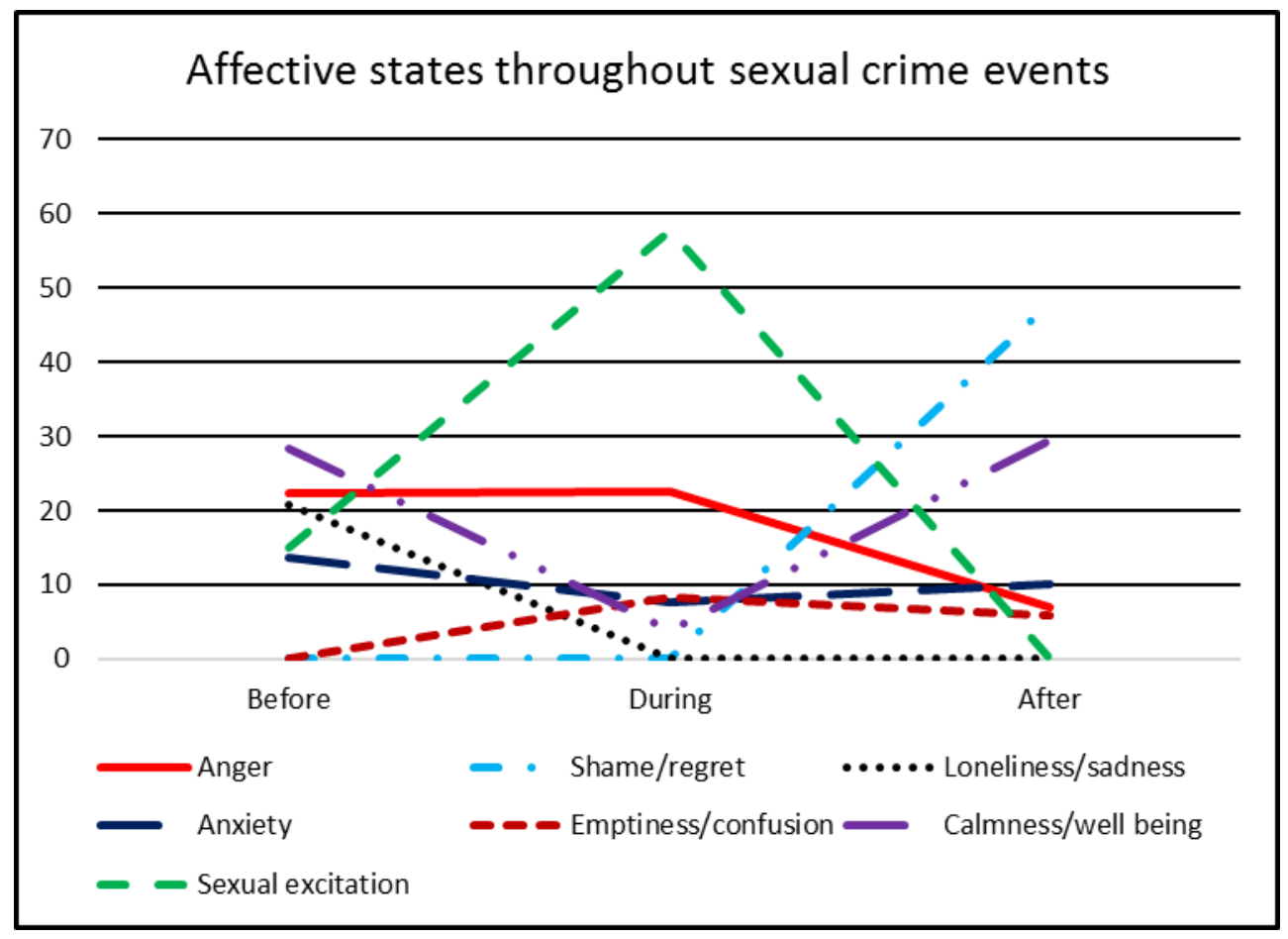


Table 1. Crime Transitions of Sexual Offender Affective States across the Crime Event (Before, During and After the Event)

\begin{tabular}{|c|c|c|c|c|c|c|c|}
\hline \multirow[t]{2}{*}{ Crime $\mathrm{T}$} & \multicolumn{7}{|c|}{ Crime $\mathbf{T}+1$} \\
\hline & Angry & Ashamed/Regretful & Lonely/Sad & Anxious & Confused & Calm/Well & Sexually excited \\
\hline Angry & $\begin{array}{l}\mathrm{T}_{1}=.61(48) \\
\mathrm{T}_{2}=.24(18)\end{array}$ & $\begin{array}{c}\mathrm{T}_{1}=.03(2) \\
\mathrm{T}_{2}=.29(22)\end{array}$ & $\begin{array}{l}\mathrm{T}_{1}=.04(3) \\
\mathrm{T}_{2}=.05(4)\end{array}$ & $\begin{array}{l}\mathrm{T}_{1}=.01(1) \\
\mathrm{T}_{2}=.12(9)\end{array}$ & $\begin{array}{l}\mathrm{T}_{1}=.08(6) \\
\mathrm{T}_{2}=.12(9)\end{array}$ & $\begin{array}{c}\mathrm{T}_{1}=.00(0) \\
\mathrm{T}_{2}=.18(14)\end{array}$ & $\begin{array}{c}\mathrm{T}_{1}=.23(18) \\
\mathrm{T}_{2}=.00(0)\end{array}$ \\
\hline Ashamed/Regretful & $\begin{array}{l}\mathrm{T}_{1}=.00(0) \\
\mathrm{T}_{2}=.00(0)\end{array}$ & $\begin{array}{l}\mathrm{T}_{1}=.00(0) \\
\mathrm{T}_{2}=.78(7)\end{array}$ & $\begin{array}{l}\mathrm{T}_{1}=.00(0) \\
\mathrm{T}_{2}=.11(1)\end{array}$ & $\begin{array}{l}\mathrm{T}_{1}=.00(0) \\
\mathrm{T}_{2}=.00(0)\end{array}$ & $\begin{array}{l}\mathrm{T}_{1}=.00(0) \\
\mathrm{T}_{2}=.11(1)\end{array}$ & $\begin{array}{l}\mathrm{T}_{1}=.00(0) \\
\mathrm{T}_{2}=.00(0)\end{array}$ & $\begin{array}{c}\mathrm{T}_{1}=1.00(1) \\
\mathrm{T}_{2}=.00(0)\end{array}$ \\
\hline Lonely/Sad & $\begin{array}{l}\mathrm{T}_{1}=.07(5) \\
\mathrm{T}_{2}=.00(0)\end{array}$ & $\begin{array}{l}\mathrm{T}_{1}=.01(1) \\
\mathrm{T}_{2}=.25(1)\end{array}$ & $\begin{array}{l}\mathrm{T}_{1}=.00(0) \\
\mathrm{T}_{2}=.75(3)\end{array}$ & $\begin{array}{c}\mathrm{T}_{1}=.14(10) \\
\mathrm{T}_{2}=.00(0)\end{array}$ & $\begin{array}{l}\mathrm{T}_{1}=.12(9) \\
\mathrm{T}_{2}=.00(0)\end{array}$ & $\begin{array}{l}\mathrm{T}_{1}=.03(2) \\
\mathrm{T}_{2}=.00(0)\end{array}$ & $\begin{array}{c}\mathrm{T}_{1}=.63(46) \\
\mathrm{T}_{2}=.00(0)\end{array}$ \\
\hline Anxious & $\begin{array}{l}\mathrm{T}_{1}=.08(4) \\
\mathrm{T}_{2}=.03(1)\end{array}$ & $\begin{array}{c}\mathrm{T}_{1}=.06(3) \\
\mathrm{T}_{2}=.62(18)\end{array}$ & $\begin{array}{l}\mathrm{T}_{1}=.00(0) \\
\mathrm{T}_{2}=.07(2)\end{array}$ & $\begin{array}{l}\mathrm{T}_{1}=.11(6) \\
\mathrm{T}_{2}=.14(4)\end{array}$ & $\begin{array}{l}\mathrm{T}_{1}=.06(3) \\
\mathrm{T}_{2}=.03(1)\end{array}$ & $\begin{array}{l}\mathrm{T}_{1}=.04(2) \\
\mathrm{T}_{2}=.11(3)\end{array}$ & $\begin{array}{c}\mathrm{T}_{1}=.65(34) \\
\mathrm{T}_{2}=.00(0)\end{array}$ \\
\hline Confused & $\begin{array}{l}\mathrm{T}_{1}=.12(3) \\
\mathrm{T}_{2}=.03(1)\end{array}$ & $\begin{aligned} \mathrm{T}_{1} & =.00(0) \\
\mathrm{T}_{2} & =.46(13)\end{aligned}$ & $\begin{array}{l}\mathrm{T}_{1}=.04(1) \\
\mathrm{T}_{2}=.11(3)\end{array}$ & $\begin{array}{l}\mathrm{T}_{1}=.24(6) \\
\mathrm{T}_{2}=.00(0)\end{array}$ & $\begin{array}{l}\mathrm{T}_{1}=.48(12) \\
\mathrm{T}_{2}=.29(8)\end{array}$ & $\begin{array}{l}\mathrm{T}_{1}=.04(1) \\
\mathrm{T}_{2}=.11(3)\end{array}$ & $\begin{array}{l}\mathrm{T}_{1}=.08(2) \\
\mathrm{T}_{2}=.00(0)\end{array}$ \\
\hline Calm/Well & $\begin{array}{c}\mathrm{T}_{1}=.20(19) \\
\mathrm{T}_{2}=.07(1)\end{array}$ & $\begin{array}{l}\mathrm{T}_{1}=.01(1) \\
\mathrm{T}_{2}=.26(4)\end{array}$ & $\begin{array}{l}\mathrm{T}_{1}=.00(0) \\
\mathrm{T}_{2}=.07(1)\end{array}$ & $\begin{array}{l}\mathrm{T}_{1}=.05(5) \\
\mathrm{T}_{2}=.07(1)\end{array}$ & $\begin{array}{l}\mathrm{T}_{1}=.03(3) \\
\mathrm{T}_{2}=.00(0)\end{array}$ & $\begin{array}{c}\mathrm{T}_{1}=.10(10) \\
\mathrm{T}_{2}=.53(8)\end{array}$ & $\begin{array}{c}\mathrm{T}_{1}=.61(59) \\
\mathrm{T}_{2}=.00(0)\end{array}$ \\
\hline Sexually excited & $\begin{array}{l}\mathrm{T}_{1}=.02(1) \\
\mathrm{T}_{2}=.02(5)\end{array}$ & $\begin{array}{c}\mathrm{T}_{1}=.00(0) \\
\mathrm{T}_{2}=.47(104)\end{array}$ & $\begin{array}{l}\mathrm{T}_{1}=.00(0) \\
\mathrm{T}_{2}=.02(4)\end{array}$ & $\begin{array}{c}\mathrm{T}_{1}=.04(2) \\
\mathrm{T}_{2}=.10(22)\end{array}$ & $\begin{array}{l}\mathrm{T}_{1}=.00(0) \\
\mathrm{T}_{2}=.01(3)\end{array}$ & $\begin{array}{c}\mathrm{T}_{1}=.00(0) \\
\mathrm{T}_{2}=.36(80)\end{array}$ & $\begin{array}{c}\mathrm{T}_{1}=.94(51) \\
\mathrm{T}_{2}=.00(0)\end{array}$ \\
\hline
\end{tabular}

$\mathrm{T}_{1}=$ Transition from before event to during event $(\mathrm{n}=380) ; \mathrm{T}_{2}=$ Transition from during event to after event $(\mathrm{n}=383)$. The dark blue diagonal represents stability trends. 
Table 2. Crime-Transitions of Sexual Offender Affective States before the Crime Event across Victims

\begin{tabular}{|c|c|c|c|c|c|c|c|}
\hline Crime $\mathrm{T}$ & & & & Crime $\mathbf{T}+1$ & & & \\
\hline & Angry & Ashamed/Regretful & Lonely/Sad & Anxious & Confused & Calm/well & Sexually excited \\
\hline Angry & $\begin{array}{l}\mathrm{T}_{1}=1.00(19) \\
\mathrm{T}_{2}=1.00\end{array}$ & $\begin{array}{l}\mathrm{T}_{1}=.00(0) \\
\mathrm{T}_{2}=.00(0)\end{array}$ & $\begin{array}{l}\mathrm{T}_{1}=.00(0) \\
\mathrm{T}_{2}=.00(0)\end{array}$ & $\begin{array}{l}\mathrm{T}_{1}=.00(0) \\
\mathrm{T}_{2}=.00(0)\end{array}$ & $\begin{array}{l}\mathrm{T}_{1}=.00(0) \\
\mathrm{T}_{2}=.00(0)\end{array}$ & $\begin{array}{l}\mathrm{T}_{1}=.00(0) \\
\mathrm{T}_{2}=.00(0)\end{array}$ & $\begin{array}{l}\mathrm{T}_{1}=.00(0) \\
\mathrm{T}_{2}=.00(0)\end{array}$ \\
\hline Ashamed/Regretful & $\begin{array}{l}\mathrm{T}_{1}=.00(0) \\
\mathrm{T}_{2}=.00(0)\end{array}$ & $\begin{array}{l}\mathrm{T}_{1}=.00(0) \\
\mathrm{T}_{2}=.00(0)\end{array}$ & $\begin{array}{l}\mathrm{T}_{1}=.00(0) \\
\mathrm{T}_{2}=.00(0)\end{array}$ & $\begin{array}{l}\mathrm{T}_{1}=.00(0) \\
\mathrm{T}_{2}=.00(0)\end{array}$ & $\begin{array}{l}\mathrm{T}_{1}=.00(0) \\
\mathrm{T}_{2}=.00(0)\end{array}$ & $\begin{array}{l}\mathrm{T}_{1}=.00(0) \\
\mathrm{T}_{2}=.00(0)\end{array}$ & $\begin{array}{l}\mathrm{T}_{1}=.00(0) \\
\mathrm{T}_{2}=.00(0)\end{array}$ \\
\hline Lonely/Sad & $\begin{array}{l}\mathrm{T}_{1}=.00(0) \\
\mathrm{T}_{2}=.13(2)\end{array}$ & $\begin{array}{l}\mathrm{T}_{1}=.00(0) \\
\mathrm{T}_{2}=.00(0)\end{array}$ & $\begin{array}{l}\mathrm{T}_{1}=.97(36) \\
\mathrm{T}_{2}=.81(13)\end{array}$ & $\begin{array}{c}\mathrm{T}_{1}=.00(00) \\
\mathrm{T}_{2}=.00(0)\end{array}$ & $\begin{array}{l}\mathrm{T}_{1}=.00(0) \\
\mathrm{T}_{2}=.00(0)\end{array}$ & $\begin{array}{l}\mathrm{T}_{1}=.03(1) \\
\mathrm{T}_{2}=.00(0)\end{array}$ & $\begin{array}{c}\mathrm{T}_{1}=.00(00) \\
\mathrm{T}_{2}=.06(1)\end{array}$ \\
\hline Anxious & $\begin{array}{l}\mathrm{T}_{1}=.00(0) \\
\mathrm{T}_{2}=.00(0)\end{array}$ & $\begin{array}{l}\mathrm{T}_{1}=.00(0) \\
\mathrm{T}_{2}=.00(0)\end{array}$ & $\begin{array}{l}\mathrm{T}_{1}=.00(0) \\
\mathrm{T}_{2}=.00(0)\end{array}$ & $\begin{array}{l}\mathrm{T}_{1}=1.00(17) \\
\mathrm{T}_{2}=1.00(14)\end{array}$ & $\begin{array}{l}\mathrm{T}_{1}=.00(0) \\
\mathrm{T}_{2}=.00(0)\end{array}$ & $\begin{array}{l}\mathrm{T}_{1}=.00(0) \\
\mathrm{T}_{2}=.00(0)\end{array}$ & $\begin{array}{l}\mathrm{T}_{1}=.00(0) \\
\mathrm{T}_{2}=.00(0)\end{array}$ \\
\hline Confused & $\begin{array}{l}\mathrm{T}_{1}=.00(0) \\
\mathrm{T}_{2}=.00(0)\end{array}$ & $\begin{array}{l}\mathrm{T}_{1}=.00(0) \\
\mathrm{T}_{2}=.00(0)\end{array}$ & $\begin{array}{l}\mathrm{T}_{1}=.00(0) \\
\mathrm{T}_{2}=.00(0)\end{array}$ & $\begin{array}{l}\mathrm{T}_{1}=.00(0) \\
\mathrm{T}_{2}=.00(0)\end{array}$ & $\begin{aligned} \mathrm{T}_{1} & =1.00(11) \\
\mathrm{T}_{2} & =1.00(5)\end{aligned}$ & $\begin{array}{l}\mathrm{T}_{1}=.00(0) \\
\mathrm{T}_{2}=.00(0)\end{array}$ & $\begin{array}{l}\mathrm{T}_{1}=.00(0) \\
\mathrm{T}_{2}=.00(0)\end{array}$ \\
\hline Calm/well & $\begin{array}{l}\mathrm{T}_{1}=.02(1) \\
\mathrm{T}_{2}=.00(0)\end{array}$ & $\begin{array}{l}\mathrm{T}_{1}=.00(0) \\
\mathrm{T}_{2}=.00(0)\end{array}$ & $\begin{array}{l}\mathrm{T}_{1}=.00(0) \\
\mathrm{T}_{2}=.00(0)\end{array}$ & $\begin{array}{l}\mathrm{T}_{1}=.02(1) \\
\mathrm{T}_{2}=.00(0)\end{array}$ & $\begin{array}{l}\mathrm{T}_{1}=.02(1) \\
\mathrm{T}_{2}=.00(0)\end{array}$ & $\begin{aligned} \mathrm{T}_{1} & =.89(39) \\
\mathrm{T}_{2} & =1.00(23)\end{aligned}$ & $\begin{array}{l}\mathrm{T}_{1}=.05(2) \\
\mathrm{T}_{2}=.00(0)\end{array}$ \\
\hline Sexually excited & $\begin{array}{l}\mathrm{T}_{1}=.04(1) \\
\mathrm{T}_{2}=.00(0)\end{array}$ & $\begin{array}{l}\mathrm{T}_{1}=.00(0) \\
\mathrm{T}_{2}=.00(0)\end{array}$ & $\begin{array}{l}\mathrm{T}_{1}=.00(0) \\
\mathrm{T}_{2}=.00(0)\end{array}$ & $\begin{array}{l}\mathrm{T}_{1}=.00(0) \\
\mathrm{T}_{2}=.00(0)\end{array}$ & $\begin{array}{l}\mathrm{T}_{1}=.04(1) \\
\mathrm{T}_{2}=.00(0)\end{array}$ & $\begin{array}{l}\mathrm{T}_{1}=.00(0) \\
\mathrm{T}_{2}=.11(1)\end{array}$ & $\begin{array}{l}\mathrm{T}_{1}=0.92(21) \\
\mathrm{T}_{2}=0.89\end{array}$ \\
\hline
\end{tabular}

$\mathrm{T}_{1}=$ Transition from victim \#1 to victim \#2 ( $\left.\mathrm{n}=139\right) ; \mathrm{T}_{2}=$ Transition from victim \#2 to victim \#3 ( $\left.\mathrm{n}=72\right)$. The dark blue diagonal represents stability trends. 
Table 3. Crime-Transitions of Sexual Offender Affective States during the Crime Event across Victims

\begin{tabular}{|c|c|c|c|c|c|c|c|}
\hline Crime $\mathrm{T}$ & & & & Crime $\mathbf{T}+1$ & & & \\
\hline & Angry & Ashamed/Regretful & Lonely/Sad & Anxious & Confused & Calm/well & Sexually excited \\
\hline Angry & $\begin{array}{l}\mathrm{T}_{1}=.79(11) \\
\mathrm{T}_{2}=1.00\end{array}$ & $\begin{array}{l}\mathrm{T}_{1}=.00(0) \\
\mathrm{T}_{2}=.00(0)\end{array}$ & $\begin{array}{l}\mathrm{T}_{1}=.00(0) \\
\mathrm{T}_{2}=.00(0)\end{array}$ & $\begin{array}{l}\mathrm{T}_{1}=.00(0) \\
\mathrm{T}_{2}=.00(0)\end{array}$ & $\begin{array}{l}\mathrm{T}_{1}=.07(1) \\
\mathrm{T}_{2}=.00(0)\end{array}$ & $\begin{array}{l}\mathrm{T}_{1}=.00(0) \\
\mathrm{T}_{2}=.00(0)\end{array}$ & $\begin{array}{l}\mathrm{T}_{1}=.14(2) \\
\mathrm{T}_{2}=.00(0)\end{array}$ \\
\hline Ashamed/Regretful & $\begin{array}{l}\mathrm{T}_{1}=.33(1) \\
\mathrm{T}_{2}=.00(0)\end{array}$ & $\begin{array}{l}\mathrm{T}_{1}=.67(2) \\
\mathrm{T}_{2}=.00(0)\end{array}$ & $\begin{array}{l}\mathrm{T}_{1}=.00(0) \\
\mathrm{T}_{2}=.00(0)\end{array}$ & $\begin{array}{l}\mathrm{T}_{1}=.00(0) \\
\mathrm{T}_{2}=.00(0)\end{array}$ & $\begin{array}{l}\mathrm{T}_{1}=.00(0) \\
\mathrm{T}_{2}=.00(0)\end{array}$ & $\begin{array}{l}\mathrm{T}_{1}=.00(0) \\
\mathrm{T}_{2}=.00(0)\end{array}$ & $\begin{array}{l}\mathrm{T}_{1}=.00(0) \\
\mathrm{T}_{2}=.00(0)\end{array}$ \\
\hline Lonely/Sad & $\begin{array}{l}\mathrm{T}_{1}=.00(0) \\
\mathrm{T}_{2}=.00(0)\end{array}$ & $\begin{array}{l}\mathrm{T}_{1}=.00(0) \\
\mathrm{T}_{2}=.00(0)\end{array}$ & $\begin{array}{l}\mathrm{T}_{1}=1.00(1) \\
\mathrm{T}_{2}=1.00(1)\end{array}$ & $\begin{array}{c}\mathrm{T}_{1}=.00(00) \\
\mathrm{T}_{2}=.00(0)\end{array}$ & $\begin{array}{l}\mathrm{T}_{1}=.00(0) \\
\mathrm{T}_{2}=.00(0)\end{array}$ & $\begin{array}{l}\mathrm{T}_{1}=.00(0) \\
\mathrm{T}_{2}=.00(0)\end{array}$ & $\begin{array}{c}\mathrm{T}_{1}=.00(00) \\
\mathrm{T}_{2}=.00(0)\end{array}$ \\
\hline Anxious & $\begin{array}{l}\mathrm{T}_{1}=.00(0) \\
\mathrm{T}_{2}=.00(0)\end{array}$ & $\begin{array}{l}\mathrm{T}_{1}=.00(0) \\
\mathrm{T}_{2}=.00(0)\end{array}$ & $\begin{array}{l}\mathrm{T}_{1}=.00(0) \\
\mathrm{T}_{2}=.00(0)\end{array}$ & $\begin{array}{l}\mathrm{T}_{1}=1.00(11) \\
\mathrm{T}_{2}=1.00(6)\end{array}$ & $\begin{array}{l}\mathrm{T}_{1}=.00(0) \\
\mathrm{T}_{2}=.00(0)\end{array}$ & $\begin{array}{l}\mathrm{T}_{1}=.00(0) \\
\mathrm{T}_{2}=.00(0)\end{array}$ & $\begin{array}{l}\mathrm{T}_{1}=.00(0) \\
\mathrm{T}_{2}=.00(0)\end{array}$ \\
\hline Confused & $\begin{array}{l}\mathrm{T}_{1}=.00(0) \\
\mathrm{T}_{2}=.00(0)\end{array}$ & $\begin{array}{l}\mathrm{T}_{1}=.00(0) \\
\mathrm{T}_{2}=.00(0)\end{array}$ & $\begin{array}{l}\mathrm{T}_{1}=.00(0) \\
\mathrm{T}_{2}=.00(0)\end{array}$ & $\begin{array}{l}\mathrm{T}_{1}=.00(0) \\
\mathrm{T}_{2}=.00(0)\end{array}$ & $\begin{aligned} \mathrm{T}_{1} & =.63(5) \\
\mathrm{T}_{2} & =1.00(2)\end{aligned}$ & $\begin{array}{l}\mathrm{T}_{1}=.12(1) \\
\mathrm{T}_{2}=.00(0)\end{array}$ & $\begin{array}{l}\mathrm{T}_{1}=.25(2) \\
\mathrm{T}_{2}=.00(0)\end{array}$ \\
\hline Calm/well & $\begin{array}{l}\mathrm{T}_{1}=.00(0) \\
\mathrm{T}_{2}=.00(0)\end{array}$ & $\begin{array}{l}\mathrm{T}_{1}=.00(0) \\
\mathrm{T}_{2}=.00(0)\end{array}$ & $\begin{array}{l}\mathrm{T}_{1}=.00(0) \\
\mathrm{T}_{2}=.00(0)\end{array}$ & $\begin{array}{l}\mathrm{T}_{1}=.00(0) \\
\mathrm{T}_{2}=.00(0)\end{array}$ & $\begin{array}{l}\mathrm{T}_{1}=.00(0) \\
\mathrm{T}_{2}=.00(0)\end{array}$ & $\begin{array}{c}\mathrm{T}_{1}=.80(4) \\
\mathrm{T}_{2}=1.00(3)\end{array}$ & $\begin{array}{l}\mathrm{T}_{1}=.20(1) \\
\mathrm{T}_{2}=.00(0)\end{array}$ \\
\hline Sexually excited & $\begin{array}{l}\mathrm{T}_{1}=.03(3) \\
\mathrm{T}_{2}=.02(1)\end{array}$ & $\begin{array}{l}\mathrm{T}_{1}=.00(0) \\
\mathrm{T}_{2}=.00(0)\end{array}$ & $\begin{array}{l}\mathrm{T}_{1}=.00(0) \\
\mathrm{T}_{2}=.00(0)\end{array}$ & $\begin{array}{l}\mathrm{T}_{1}=.01(1) \\
\mathrm{T}_{2}=.02(1)\end{array}$ & $\begin{array}{l}\mathrm{T}_{1}=.00(0) \\
\mathrm{T}_{2}=.00(0)\end{array}$ & $\begin{array}{l}\mathrm{T}_{1}=.00(0) \\
\mathrm{T}_{2}=.02(1)\end{array}$ & $\begin{array}{l}\mathrm{T}_{1}=.96(107) \\
\mathrm{T}_{2}=.94(56)\end{array}$ \\
\hline
\end{tabular}

$\mathrm{T}_{1}=$ Transition from victim \#1 to victim \#2 ( $\left.\mathrm{n}=153\right)$; $\mathrm{T}_{2}=$ Transition from victim \#2 to victim \#3 $(\mathrm{n}=74)$. The dark blue diagonal represents stability trends. 
Table 4. Crime-Transitions of Sexual Offender Affective States after the Crime Event across Victims

\begin{tabular}{|c|c|c|c|c|c|c|c|}
\hline Crime $\mathrm{T}$ & & & & Crime $\mathbf{T}+1$ & & & \\
\hline & Angry & Ashamed/Regretful & Lonely/Sad & Anxious & Confused & Calm/well & Sexually excited \\
\hline Angry & $\begin{array}{l}\mathrm{T}_{1}=1.00(5) \\
\mathrm{T}_{2}=1.00(2)\end{array}$ & $\begin{array}{l}\mathrm{T}_{1}=.00(0) \\
\mathrm{T}_{2}=.00(0)\end{array}$ & $\begin{array}{l}\mathrm{T}_{1}=.00(0) \\
\mathrm{T}_{2}=.00(0)\end{array}$ & $\begin{array}{l}\mathrm{T}_{1}=.00(0) \\
\mathrm{T}_{2}=.00(0)\end{array}$ & $\begin{array}{l}\mathrm{T}_{1}=.00(0) \\
\mathrm{T}_{2}=.00(0)\end{array}$ & $\begin{array}{l}\mathrm{T}_{1}=.00(0) \\
\mathrm{T}_{2}=.00(0)\end{array}$ & $\begin{array}{l}\mathrm{T}_{1}=.00(0) \\
\mathrm{T}_{2}=.00(0)\end{array}$ \\
\hline Ashamed/Regretful & $\begin{array}{l}\mathrm{T}_{1}=.02(1) \\
\mathrm{T}_{2}=.00(0)\end{array}$ & $\begin{array}{l}\mathrm{T}_{1}=.94(60) \\
\mathrm{T}_{2}=.97(29)\end{array}$ & $\begin{array}{l}\mathrm{T}_{1}=.00(0) \\
\mathrm{T}_{2}=.00(0)\end{array}$ & $\begin{array}{l}\mathrm{T}_{1}=.02(1) \\
\mathrm{T}_{2}=.00(0)\end{array}$ & $\begin{array}{l}\mathrm{T}_{1}=.00(0) \\
\mathrm{T}_{2}=.00(0)\end{array}$ & $\begin{array}{l}\mathrm{T}_{1}=.02(1) \\
\mathrm{T}_{2}=.03(1)\end{array}$ & $\begin{array}{l}\mathrm{T}_{1}=.00(0) \\
\mathrm{T}_{2}=.00(0)\end{array}$ \\
\hline Lonely/Sad & $\begin{array}{l}\mathrm{T}_{1}=.00(0) \\
\mathrm{T}_{2}=.00(0)\end{array}$ & $\begin{array}{l}\mathrm{T}_{1}=.00(0) \\
\mathrm{T}_{2}=.00(0)\end{array}$ & $\begin{array}{l}\mathrm{T}_{1}=1.00(8) \\
\mathrm{T}_{2}=1.00(5)\end{array}$ & $\begin{array}{c}\mathrm{T}_{1}=.00(00) \\
\mathrm{T}_{2}=.00(0)\end{array}$ & $\begin{array}{l}\mathrm{T}_{1}=.00(0) \\
\mathrm{T}_{2}=.00(0)\end{array}$ & $\begin{array}{l}\mathrm{T}_{1}=.00(0) \\
\mathrm{T}_{2}=.00(0)\end{array}$ & $\begin{array}{c}\mathrm{T}_{1}=.00(00) \\
\mathrm{T}_{2}=.00(0)\end{array}$ \\
\hline Anxious & $\begin{array}{l}\mathrm{T}_{1}=.00(0) \\
\mathrm{T}_{2}=.00(0)\end{array}$ & $\begin{array}{l}\mathrm{T}_{1}=.00(0) \\
\mathrm{T}_{2}=.00(0)\end{array}$ & $\begin{array}{l}\mathrm{T}_{1}=.00(0) \\
\mathrm{T}_{2}=.00(0)\end{array}$ & $\begin{array}{l}\mathrm{T}_{1}=1.00(13) \\
\mathrm{T}_{2}=1.00\end{array}$ & $\begin{array}{l}\mathrm{T}_{1}=.00(0) \\
\mathrm{T}_{2}=.00(0)\end{array}$ & $\begin{array}{l}\mathrm{T}_{1}=.00(0) \\
\mathrm{T}_{2}=.00(0)\end{array}$ & $\begin{array}{l}\mathrm{T}_{1}=.00(0) \\
\mathrm{T}_{2}=.00(0)\end{array}$ \\
\hline Confused & $\begin{array}{l}\mathrm{T}_{1}=.00(0) \\
\mathrm{T}_{2}=.00(0)\end{array}$ & $\begin{array}{l}\mathrm{T}_{1}=.00(0) \\
\mathrm{T}_{2}=.00(0)\end{array}$ & $\begin{array}{l}\mathrm{T}_{1}=.00(0) \\
\mathrm{T}_{2}=.00(0)\end{array}$ & $\begin{array}{l}\mathrm{T}_{1}=.00(0) \\
\mathrm{T}_{2}=.00(0)\end{array}$ & $\begin{aligned} \mathrm{T}_{1} & =.75(3) \\
\mathrm{T}_{2} & =1.00(2)\end{aligned}$ & $\begin{array}{l}\mathrm{T}_{1}=.25(1) \\
\mathrm{T}_{2}=.00(0)\end{array}$ & $\begin{array}{l}\mathrm{T}_{1}=.00(0) \\
\mathrm{T}_{2}=.00(0)\end{array}$ \\
\hline Calm/well & $\begin{array}{l}\mathrm{T}_{1}=.00(0) \\
\mathrm{T}_{2}=.00(0)\end{array}$ & $\begin{array}{l}\mathrm{T}_{1}=.11(5) \\
\mathrm{T}_{2}=.00(0)\end{array}$ & $\begin{array}{l}\mathrm{T}_{1}=.00(0) \\
\mathrm{T}_{2}=.00(0)\end{array}$ & $\begin{array}{l}\mathrm{T}_{1}=.02(1) \\
\mathrm{T}_{2}=.00(0)\end{array}$ & $\begin{array}{l}\mathrm{T}_{1}=.00(0) \\
\mathrm{T}_{2}=.00(0)\end{array}$ & $\begin{aligned} \mathrm{T}_{1} & =.87(39) \\
\mathrm{T}_{2} & =1.00(26)\end{aligned}$ & $\begin{array}{l}\mathrm{T}_{1}=.00(0) \\
\mathrm{T}_{2}=.00(0)\end{array}$ \\
\hline Sexually excited & $\begin{array}{l}\mathrm{T}_{1}=.00(0) \\
\mathrm{T}_{2}=.00(0)\end{array}$ & $\begin{array}{l}\mathrm{T}_{1}=.00(0) \\
\mathrm{T}_{2}=.00(0)\end{array}$ & $\begin{array}{l}\mathrm{T}_{1}=.00(0) \\
\mathrm{T}_{2}=.00(0)\end{array}$ & $\begin{array}{l}\mathrm{T}_{1}=.00(0) \\
\mathrm{T}_{2}=.00(0)\end{array}$ & $\begin{array}{l}\mathrm{T}_{1}=.00(0) \\
\mathrm{T}_{2}=.00(0)\end{array}$ & $\begin{array}{l}\mathrm{T}_{1}=.00(0) \\
\mathrm{T}_{2}=.00(0)\end{array}$ & $\begin{array}{l}\mathrm{T}_{1}=1.00 \\
\mathrm{~T}_{2}=1.00\end{array}$ \\
\hline
\end{tabular}

$\mathrm{T}_{1}=$ Transition from victim \#1 to victim \#2 $(\mathrm{n}=139)$; $\mathrm{T}_{2}=$ Transition from victim \#2 to victim \#3 $(\mathrm{n}=70)$. The dark blue diagonal represents stability trends. 
Table 5. Multinomial Logistic Regression Model on Affective States before Crime

\begin{tabular}{|l|l|l|}
\hline Variable & $\begin{array}{l}\text { Affective State } \\
\text { Calm }\end{array}$ & Sexual excitation \\
\hline $\begin{array}{l}\text { Victim personality } \\
\text { attractiveness }\end{array}$ & $1.04(.893-1.21)$ & $\Psi(95 \% \mathrm{CI})$ \\
\hline $\begin{array}{l}\text { Victim physical attractiveness } \\
\text { Used alcohol before crime }\end{array}$ & $.895(.741-1.08)$ & $1.07(.897-1.26)$ \\
\hline $\begin{array}{l}\text { Perceived high risk of } \\
\text { apprehension before crime }\end{array}$ & $.685(.332-1.416)$ & $.324(.147-.713) * *$ \\
\hline Was not family-related & $2.27(1.10-4.69)^{*}$ & $.883(.392-1.99)$ \\
\hline Model fit & $31.18^{* * *}$ & $.735(.312-1.73)$ \\
\hline Nagelkerke $\mathrm{R}^{2}$ & .167 & \\
\hline
\end{tabular}

Abbreviations: $\Psi=$ Odds ratio, $\mathrm{CI}=$ Confidence Intervals. $\mathrm{N}=196$

Note: Reference category is anger; $* p \leq .05, * * p \leq .01, * * * p \leq .001$. 
Table 6. Logistic Regression Model of Affective States during Crime

\begin{tabular}{|l|l|}
\hline Variable & $\begin{array}{l}\text { Affective State } \\
\text { Anger }\end{array}$ \\
\hline Victim personality attractiveness & $\Psi(95 \% \mathrm{CI})$ \\
\hline Victim physical attractiveness & $.858(.749-.983)^{*}$ \\
\hline Used alcohol before crime & $.973(.826-1.15)$ \\
\hline $\begin{array}{l}\text { Perceived high risk of apprehension before } \\
\text { crime }\end{array}$ & $4.55(2.45-8.45)^{* * *}$ \\
\hline Was not family-related & $1.61(.855-3.03)$ \\
\hline Model Chi-square & $.960(.506-1.82)$ \\
\hline Nagelkerke $\mathrm{R}^{2}$ & $37.01 * * *$ \\
\hline
\end{tabular}

Abbreviations: $\Psi=$ Odds ratio, $\mathrm{CI}=$ Confidence Intervals. $\mathrm{N}=111$

Note: Reference category is sexual excitation; ${ }^{*} p \leq .05,{ }^{*} p \leq .01,{ }^{* * *} p \leq .001$. 
Table 7. Logistic Regression Model of Affective States after Crime

\begin{tabular}{|l|l|}
\hline Variable & $\begin{array}{l}\text { Affective State } \\
\text { Shame/regret }\end{array}$ \\
\hline Victim personality attractiveness & $1.03(.912-1.17)$ \\
\hline Victim physical attractiveness & $1.02(.874-1.19)$ \\
\hline Used alcohol before crime & $1.02(.586-1.77)$ \\
\hline $\begin{array}{l}\text { Perceived high risk of apprehension before } \\
\text { crime }\end{array}$ & $1.06(.603-1.86)$ \\
\hline Was not family-related & $.534(.308-.925)^{*}$ \\
\hline Model Chi-square & 6.16 \\
\hline Nagelkerke $\mathrm{R}^{2}$ & .035 \\
\hline
\end{tabular}

Abbreviations: $\Psi=$ Odds ratio, $\mathrm{CI}=$ Confidence Intervals. $\mathrm{N}=238$

Note: Reference category is calm/well-being; ${ }^{*} p \leq .05,{ }^{*} p \leq .01, * * * p \leq .001$. 